\title{
Students' perspectives on e-portfolio development and implementation: A case study in Taiwanese higher education
}

\author{
Pei-Hsuan Hsieh, Chun-I Lee \\ National Cheng Kung University, Taiwan \\ Wei-Fan Chen \\ The Pennsylvania State University
}

\begin{abstract}
This study explores students' perceptions related to the implementation of e-portfolios in the context of Taiwanese higher education. Thirty Taiwanese university students were interviewed, and data analysis includes 14 interviewees' e-portfolios and responses to 281 valid surveys from non-interviewed students. The study presents students' perspectives using textual descriptions and visual presentations related to developing e-portfolios. A three-stage model developed by the first author links five critical success factors for implementing e-portfolios in Taiwan. Overall, the students' perceived usefulness, university support, and e-portfolio audiences (i.e., educators, employers, and friends) as well as intentions to visit e-portfolios are the major components used to promote e-portfolios in Taiwanese higher education. The findings of the study indicate that the value of developing an e-portfolio can be enhanced by using incentives such as design contests or encouragement through various other activities (e.g., class activities, team projects, and extracurricular activities). Accessibility, interactivity, and ownership are university students' concerns when they are deciding to develop e-portfolios. For implementing a system of e-portfolios, the study suggests guidelines that can become important references for countries with similar cultural backgrounds in higher education. New insights relevant for scholars from Western countries also appear at the end.
\end{abstract}

\section{Introduction}

New forms of assessment involve participation in class activities, team projects, and discussions of coursework with classmates and teachers. In this learning context, the electronic portfolio (e-portfolio) represents an active and creative learning tool consisting of both authentic learning and reflective thinking (Barrett \& Carney, 2005; Buzzetto-More \& Nicole, 2010; Lambe, McNair, \& Smith, 2013; Zubizrreta, 2009). The notion of using e-portfolios on campus for learning, teacher training, and as tools for performance assessment began to flourish in the early 1990s, particularly in Western countries (Clark \& Eynon, 2009; Hart Research Associates, 2009; Mason, Pegler, \& Weller, 2004). An e-portfolio is a personalised online space on which authors post previous learning experiences, current working progress, and future career plans (Abrami \& Barrett, 2005; Barrett \& Carney, 2005; Lopez-Fernandez \& Rodriguez-Illera, 2009; MacDonald, Liu, Lowell, Tsai, \& Lohr, 2004). Moreover, with the aid of multimedia technologies, every meaningful, digitalised artefact and reflective statement can appear for an array of audiences (e.g., educators, employers, and friends), anywhere, and within a particular time frame, even throughout the lifespan of an individual (MacDonald et al., 2004; Stefani, Mason, \& Pegler, 2007). Based on specific purposes, such as continuous learning, professional development, competence demonstration, performance evaluation, and job seeking, e-portfolio authors can determine the appearance and content of their e-portfolios (Ford, Hartley, \& Lumsden, 2008).

Most prior studies discussing topics pertinent to implementing e-portfolios addressed issues related to training and evaluating students' learning performance (Ntuli, Keengwe, \& Kyei-Blankson, 2009). The targeted participants of those studies were either classroom students or teachers, including in- and pre-service teachers (Herner-Patnode \& Lee, 2009; Johnson, Hsieh, \& Kidwai, 2007; Jun, Anthony, Achrazoglou, \& Coghill-Behrends, 2007; Kocoglu, 2008; Ntuli et al., 2009; Tsai, Lowell, Liu, MacDonald, \& Lohr, 2004). In addition, most prior studies have used mixed methods that include qualitative approaches (e.g., interviews and documents) to reveal e-portfolio authors' deeper feelings and thoughts since quantitative approaches (e.g., 
statistical analyses and surveys) can only disclose the authors' generalised perceptions (Abrami \& Barrett, 2005; Dalton, 2007). More and more recent studies have adopted mixed methods to explore user attitudes and perceptions with regard to the use of e-portfolios; however, the scale of both prior and recent studies is small, within particular curricula or programs, and all indicate that the creation of e-portfolios is a course requirement or a tool for evaluating performance (Kocoglu, 2008; Lin, 2008; Lopez-Fernandez \& Rodriguez-Illera, 2009; Taylor, Dunbar-Hall, \& Rowley, 2012; Tonni \& Oliver, 2013). Thus, beyond the context of one class and one campus, exploration of student perceptions in the context of higher education for implementing e-portfolios has not had full investigation, so far, particularly in Taiwan. This study proposes to reveal student experiences with the construction of e-portfolios and perceptions related to their implementation in Taiwanese institutions of higher education.

\section{Literature review}

\section{Introduction to e-portfolios}

A portfolio, whether electronic or paper-based, is more than an organised collection of work selected and then presented to demonstrate an author's learning progress and intellectual growth over time (Lopez-Fernandez \& Rodriguez-Illera, 2009; Mason et al., 2004). The concept of portfolio construction has been applied in many disciplines, such as art, music, sciences, architecture, composition, nursing, and teacher and medical education since the mid-1980s (Clark \& Eynon, 2009; van Tartwijk, Driessen, van der Vleuten, \& Stokking, 2007). Paper-based portfolios are arrangements of collections of work stored in physical boxes, binders, or file folders. Compared to paper-based portfolios, the major feature of e-portfolios is the potential to include multimedia elements (i.e., text, graphics, video, audio, photos, and animation) connected by hyperlinks to show a comprehensive rendition of reflective thoughts throughout the learning process (Barrett \& Carney, 2005). The portfolio author can decide to publish on the Internet or use permanent media such as CD-ROMs or DVDs (Jun et al., 2007). Different types of documented and digitalised content in e-portfolios can appear as technological artefacts to present unique features (MacDonald et al., 2004; Stefani et al., 2007). For example, organised, searchable, and transportable e-portfolios allow rethinking of an entire curriculum that can be used for faculty evaluations, program assessments, certifications of students' work, and accreditation (Chang, Liang, Tseng, Tseng, \& Chen, 2013). Extended use of e-portfolios can be applied widely for a multitude of purposes (e.g., advanced studies, job applications) and audiences (e.g., educators, employers, and friends), especially when integrating mobile and Web 2.0 technologies in systems employing e-portfolios (Barrett, 2010; Ford et al., 2008).

In addition, depending on the technical skills of an e-portfolio's author, the complexity of a developed e-portfolio varies, and authors may employ generic tools (GT) or customised systems (CS) (Gibson \& Barrett, 2003). Advanced authors, who are capable of manipulating common software tools including word processing, HTML authoring tools, portable document formats (PDFs), multimedia, video, and blogs, usually adopt the GT approach. In contrast, the CS approach uses server-based customised systems to ease the process of collecting and maintaining work in a well-organised way, which is useful for novices (Barrett \& Carney, 2005). The two major distinctions between these two approaches are (1) the amount of autonomy needed to develop and control e-portfolios (GT) and (2) the degree to which specialised technologies allow management (CS) (Jun et al., 2007). Overall, to gain maximum benefit from GT and CS approaches, e-portfolio systems can incorporate flexible and creative developmental processes (Gibson \& Barrett, 2003; Jun et al., 2007; Ntuli et al., 2009).

\section{User perceptions of e-portfolios}

Perception is an attitudinal factor, influenced by behavioural beliefs (i.e., beliefs about outcome, evaluation of outcome) and, based on the theory of reasoned action (TRA) proposed by Fishbein and Ajzen (1975), further affects behavioural intention. Also, according to the TRA, subject social norms, affected by normative beliefs (i.e., social references, motivation to comply), can influence users' behavioural intentions (Fishbein \& Ajzen, 1975). The TRA focuses on exploring the effects of beliefs (both behavioural and normative), attitudes, and 
subjective social norms on users' behavioural intentions. Thus, by employing these variables, careful discussion of the perceptions of e-portfolio authors is possible, especially in terms of predicting future use of e-portfolios. The TRA is the theoretical foundation for this study; however, instead of presenting study results in a theoretical framework, rich descriptions of user experiences with, and perceptions of, the use of e-portfolios are presented.

Prior studies have explored e-portfolio authors' perspectives on implementing e-portfolios and have been primarily conducted through qualitative approaches (e.g., interviews and documents) to obtain rich descriptions from the authors (Kocoglu, 2008; Ntuli et al., 2009; Tsai et al., 2004). Some other studies have adopted mixed methods to incorporate quantitative approaches (e.g., statistical analyses and surveys) (Herner-Patnode \& Lee, 2009; Johnson et al., 2007; Jun et al., 2007; Lin, 2008; Taylor et al., 2012; Tonni \& Oliver, 2013). A summary of the literature concerning user perceptions of e-portfolios for both students and teachers indicates that qualitative studies reveal the authors' feelings and thoughts more so than quantitative studies (Abrami \& Barrett, 2005; Dalton, 2007). Despite wide promotion of e-portfolio use, author or learner involvement has been shown to be a key issue in both the utility and feasibility of implementing e-portfolios (Lumsden, 2007). Thus, a greater understanding of users' thoughts and feelings contributes to the successful launching of e-portfolio programs (Dalton, 2007; Johnson et al., 2007; Tsai et al., 2004). Further investigation into user experiences with, and perceptions of, using e-portfolios on a large scale or in a nation-wide study is necessary and will be fruitful when such a study uses qualitative or mixed-method approaches.

\section{E-portfolio implementation in Taiwanese higher education}

The Taiwanese government recently recognised the importance of e-portfolio use in higher education and emphasised the inclusion of a more international perspective when implementing this activity and its technology as elements of pedagogy. The notion of e-portfolio use in Taiwanese higher education originates from a significant campaign, "ePortfolio for All," launched by the European Institute for E-Learning (EIfEL) in 2003 (http://www.eife-l.org/activities/campaigns). The main goal of this campaign was to allow all European citizens to have access to an e-portfolio by 2010. The Taiwanese government adopted the EIfEL perspective to promote a program for implementing e-portfolios in higher education beginning in 2007 (Ministry of Education, 2015). Also, Taiwan's National Youth Commission (NYC, 2012) highlighted the urgent need to propagate the use of e-portfolios to improve young people's ability to respond to employment demands arising from the marketplace. The expectation is that students will engage in ongoing self-reflection related to professional development, improve their individual competitive advantages, identify areas of academic interest, fine-tune directions for professional development, and promote employment possibilities before graduation by continuously expanding and enhancing the content of their e-portfolios. Ultimately, e-portfolio implementation enables an educational program to closely connect with students' future career plans. Overall, the rapid emergence of e-portfolios forced Taiwan's government and academic institutions to re-examine the current status of learning-related practices in the context of their educational policies.

Taiwan's Ministry of Education has encouraged institutions of higher education to educate students in methods of using free online data storage to allow creation of e-portfolios and demonstrate achievements in academics and various other activities (Ministry of Education, 2015). As encouragement, students have invitational opportunities to participate in campus-wide contests. More and more Taiwanese higher educational institutions have begun emphasising implementation of e-portfolios to record students' learning experiences and achievements throughout their academic careers. However, the Taiwanese government has no clear plan to promote e-portfolio implementation, and consequently, evaluating students' e-portfolios with standardised criteria is impossible for teachers. From a dataset created by the NYC (2012) in a national initiative, the "Project for Enhancing Implementation of Youth Employment," 52 universities (36 academic and 16 teaching universities) in Taiwan that have in-place processes for e-portfolios for all students were identified. Specifically, 15 institutions (eight academic universities and seven teaching universities) hold campus-wide e-portfolio contests for their students. Taiwanese students' experiences with developing e-portfolio and descriptions of their perceptions of using e-portfolios in such educational contexts are worthy of exploration. 


\section{Research methodology}

\section{Participants}

Interviewees were purposefully selected who could provide the richest information, the most significant insights, and an in-depth understanding of the phenomenon of interest, as opposed to empirical generalisations from a sample of a population (Babbie, 2007; Patton, 2002). Therefore, this study began with a thorough investigation of systems for e-portfolios in public, academic, and technological universities and universities recommended by the NYC. As a result, the dataset includes 30 interviewees from 15 universities (Table 1) (i.e., two students per institution from eight academic and seven teaching universities). The selected universities are among those identified as having promoted implementation of e-portfolios with campus-wide contests. The participants comprised two groups. Group I (15 participants) consisted of the winners of campus-wide competitions (i.e., the designs of their e-portfolios ranked among the top three in the contests). Group II (15 participants) consisted of individuals who had awareness of the e-portfolio contests but had no interest in participating and therefore remained uninvolved in any contests. Selection of the participants in Group II occurred via recommendations from members of Group I. Notably, Group II had some awareness of e-portfolios, and some had created personal e-portfolios.

Table 1

Interviewees' backgrounds

\begin{tabular}{lcc}
\hline (Attribute/Count) & Group I (15) & Group II (15) \\
\hline Demographics & & \\
$\quad$ Gender (male, female) & 4,11 & 6,9 \\
$\quad$ Experience with website design (yes, no) & 9,6 & 5,10 \\
Experience of e-portfolio use & 15 & 12 \\
Aware of e-portfolio contests & second (6), third (5) & first (4), fourth (4) \\
Year when learned about e-portfolios & $4,2,9$ & $5,-, 2$ \\
Developmental tool (CS, GT, hybrid) & 4,8 & - \\
Update content (never, every semester) & 14 & 12 \\
Backup e-portfolio in personal computer & - & 9 \\
View other e-portfolios & 7 & 3,3 \\
Perceptions of e-portfolio use & 7,2 & \\
Purpose: job seeking or school application & & \\
Audience (employer, school committee) &
\end{tabular}

\section{Interview process}

This study is an attempt to discover college/university students' innermost feelings with regard to the intrinsic value of e-portfolios. Their engagement in using e-portfolios likely best describes their perceptions of their own development with such systems. However, the students' varied experiences and perspectives towards e-portfolio use cannot be elaborated on in detail by responses to predetermined questions with limited ranges of responses (Patton, 2002). Thus, qualitative research is undertaken to holistically view the use of e-portfolios in higher education, in which the participants' opinions are honest and forthright (Creswell, 2003). A semi-structured form for interviews is the most effective method by which to conduct this type of research since the structure and the quality of data obtained balance flexibly (Gillham, 2005). The semi-structured form of interview used in this study effectively collects rich descriptions from interviewees who answered open-ended questions, without allowing the discussions to drift too far from the focus of the research (Gillham, 2005). Interviewees were requested to respond to open-ended questions, but the direction of discussion was controlled to remain on topic. The sample size does not represent a major concern for validity because meaningfulness and insights generated by rich descriptions are the focuses of the study (Patton, 2002). 
When preparing for the interview, Google-based searches of web portfolio systems in Taiwanese colleges/universities determined each academic institution's level of e-portfolio development. This study targeted public colleges/universities and outstanding private, academic and technological, colleges/universities, as recommended by the NYC. If the information regarding e-portfolio development was not available or inadequate from websites, direct contact with administrative units at universities provided clarification. A telephone-based survey obtained initial insight for the strategies universities adopted to promote e-portfolios, methods for developing e-portfolio systems, and most importantly, existence of contests for excellence. This preliminary investigation identified the students for interviews and directions for the questions.

Before the interviews were conducted, every participant signed an informed consent release and then completed a preliminary survey, which gathered personal background information and a brief, written description of experiences and perceptions regarding the implementation of e-portfolios at their university. Depending on participant preferences, options for actual interviews could be computer-mediated communication (e.g., Skype, a voice over Internet protocol (VOIP) service), face-to-face, or telephone conversations. During the interviews, tape-recordings and written notes documented participant responses. Most "why” and "how” queries probed for detailed statements (Babbie, 2007; Gillham, 2005).

After the interviews, the participants had an opportunity to review the transcripts, which were typed in Chinese to ensure the accuracy of the data. Since the preliminary survey provided contact information, continuous interactions via email and Skype easily double-checked responses to the interview questions and confirmed the content of the transcripts. After the interviewees acknowledged the data from the interviews to be correct, the next tasks involved identifying recurring words and ideas to find significant conceptual themes and patterns regarding e-portfolio use. Further inquiries requested interviewee feedback on the draft report of the data analysis, and peer debriefing improved the study's credibility.

\section{More data collection}

Other than rich descriptions, collecting different types of data and data from different sources can enhance the credibility of analysis results and obtain a dynamic representation of students' perceptions of implementing e-portfolios in Taiwanese higher educational contexts. The use of various sources of information can assist with confirming validity, improving the clarity and precision of findings, and allowing a comparison of qualitative and quantitative data (Lewis \& Ritchie, 2003). Thus, the technique in this study includes a document analysis of the participants' e-portfolios and distribution of a survey to those with awareness of e-portfolios, potential developers of e-portfolios,-non-participants in contests, and those not expressing interest in e-portfolios. In addition, a survey, similar to the one distributed to the interviewees, reached recommended additional participants via email and accessed students not directly interviewed or those who expressed no interest in developing e-portfolios. University educators (i.e., faculty members in higher education) and company recruiters (i.e., human resources or related departmental representatives) also received surveys to obtain a wider variety of perspectives of experiences with the development of e-portfolios and to improve the clarity and precision of the findings.

A document analysis was conducted to review the collection of e-portfolios created by the Group I interviewees, with their permission. The analysis strengthened the findings of the interview data and improved trustworthiness since obtaining the actual thoughts and language of the participants occurred in an unobtrusive and convenient way (Creswell, 2003). Most of the interviewees' e-portfolios were created subsequent to the 2007 Taiwanese government's promotion of the program to implement e-portfolios in higher education. Universities held campus-wide contests after governmental promotion.

Through recommendations from the Group I and Group II interviewees, college and university students not interviewed for this study received invitations to complete a survey, consisting of three sections: demographic information, e-portfolio experiences, and perceptions of implementing e-portfolios. The demographics of the 
respondents revealed their backgrounds and whether or not they had previously designed an e-portfolio. Experiences with developing e-portfolios elucidated the introduction of the concept of e-portfolios and the learning process required to construct one. Questions regarding the reasons for creating e-portfolios, prospective audiences, the value of using such systems, and the expectations for future implementation in Taiwan revealed student perceptions.

The survey distributed to educators and recruiters also contained three sections but with different questions from those to which the students responded. Demographic information, such as title and years of employment in their positions, confirmed their qualifications as audiences for e-portfolios. The section regarding experiences with e-portfolios inquired about details of methods used to view student e-portfolios, such as time used to browse and preferred content. Responses to the section regarding perceptions of implementing e-portfolios explained attitudes towards the educators' and employers' intentions to continue to visit posted e-portfolios.

\section{Data analysis methods}

Six steps were employed to analyse the data after interviewing the participants (Creswell, 2003): (1) data organisation and preparation - the process of converting verbal narratives into written texts, making later interpretation more readable and easier to distribute, (2) general data scanning - gaining a general sense of information to record common thoughts in the overall data, (3) coding transcriptions - placing qualitative data into conceptual categories, (4) description of patterns and themes - describing a pattern or a theme to identify interrelationships among categories and linking themes in a pictorial model for further examination, (5) advanced representation of themes - presenting the organisation of the patterns or themes to create interconnection among them that would contribute to developing a sound theoretical model, and (6) interpretation of findings - reporting commonalities and differences in findings based on the participants' own words.

Using the NVivo 7 computer-assisted qualitative data analysis software increased the effectiveness and efficiency of the data analysis and interpretational processes. This software also allowed efficient management, retrieval, grouping, and regrouping of a variety of qualitative data to uncover significant topics, categories, and themes. Reliability ensured through peer debriefing improved the stability and consistency of interpretations (Creswell, 2003). Two qualitative researchers and two graduate students, qualified by previous experience in qualitative data analysis, served as peer examiners for reviewing coding categories and for modifying interpretations of the outcomes of the data analyses. Also, member checking ensured the faithfulness of the participants' perceptions, and ongoing interaction with participants confirmed or disconfirmed the consistency of the interpretations of the qualitative data and ensured data validity. The final revision adopted input from peer feedback to remove bias.

In addition, consistent standards applied to reviews of the websites created from the e-portfolios of the interviewees in Group I allowed the observation of behaviour related to updating e-portfolios and verifying the authenticity of interview statements. Written notations recorded significant discoveries from analyses of participant e-portfolios on websites. Briefly, the inclusion of quotes from the interviewees and their reflective statements shown on websites containing e-portfolios demonstrates the value of the findings of this study. Finally, for the survey responses, SPSS $15^{\odot}$ statistical package was used to analyse the perceptions of non-interviewed students.

\section{Research results}

\section{Descriptions of experiences from Group I}

According to the Group I interviewee descriptions, introduction to the implementation of e-portfolios occurred through teachers and administrators at their schools (here and thereafter the term schools refers to the participants' colleges and universities). However, the term e-portfolio was unclear initially since 
translations used various Chinese words, and the interviewees developed their own definitions. The university administrators and teachers usually encourage students to develop their own e-portfolios by assigning various activities (e.g., class activities, team projects, and extracurricular activities), so as to help them realise potential benefits, such as demonstration of learning capability in the job market. During the process of developing e-portfolios, student motivations for developing e-portfolios certainly involved attaining awards and honours in contests. However, development was often rushed due to heavy coursework commitments, many curricular and extracurricular activities, and part-time employment:

I was rushed to develop my own e-portfolio because of time constraints. I had to explore it by myself and then upload all materials before the contest deadline. (code \# GI_03)

If time permitted, the interviewees maintained motivation to update their e-portfolios in order to share distinctly individual learning experiences, meaningful events in their daily lives, and significant achievements in extracurricular activities. They carefully considered their design layouts and included materials after exploring the elements and the structures of some existing examples. Difficulties with integrating multimedia were among their concerns when schools did not provide predefined formats. Some interviewees hoped to be able to log onto their e-portfolios after graduation:

I am not sure if I can continue using it after graduation. Hence, I removed all my materials from this system and am still searching for a better space to upload them. (code \# GI_04)

In addition, the interviewees strongly agreed that interacting with peers and teachers via e-portfolios motivated them to make frequent use of the system. Through providing suggestions and receiving feedback, the interviewees reflected on their learning and also made new friends. They anticipated that platforms for e-portfolios could be integrated with Web 2.0 features and become popular as blogs and social networking websites, such as Facebook and Plurk, thereby facilitating real-time communicative channels in an online space:

I also hope others give me feedback, such as telling me that they have read my postings in a blog or something and then give me some support, just like the features provided in Wretch. You can reply to a message and then interact with others, so I could also make friends through it [e-portfolio]. (code \# GI_06)

However, some of the interviewees mentioned concerns about privacy of data and security, regardless of their willingness to display rich materials in their e-portfolios. If the school servers had no rigid access control, everyone logging on to the Internet could easily access websites containing e-portfolios, download personal information, and copy artefacts. Fortunately, some academic institutions authorised students to decide whether or not their confidential data should be disclosed:

Since someone might have the bad idea to use the data from e-portfolios, my university gives us an option to open or not open our data. (code \# GI_07)

Based on these descriptions, Group I interviewee perspectives for developing e-portfolios are apparently value-oriented (Figure 1, left side). By learning from good examples and identifying audiences for e-portfolios, these students acquired methods for selecting and organising memorable artefacts for posting. They also attempted to enrich their e-portfolios with multimedia elements despite concerns about confidentiality, ownership, privacy, and security. Accomplishing their purposes for creating e-portfolios (e.g., winning an award in a contest, presenting and sharing learning experiences vividly with multimedia, interacting with peers and teachers, demonstrating competence to potential employers) inspired the interviewees to continue development after graduation. 


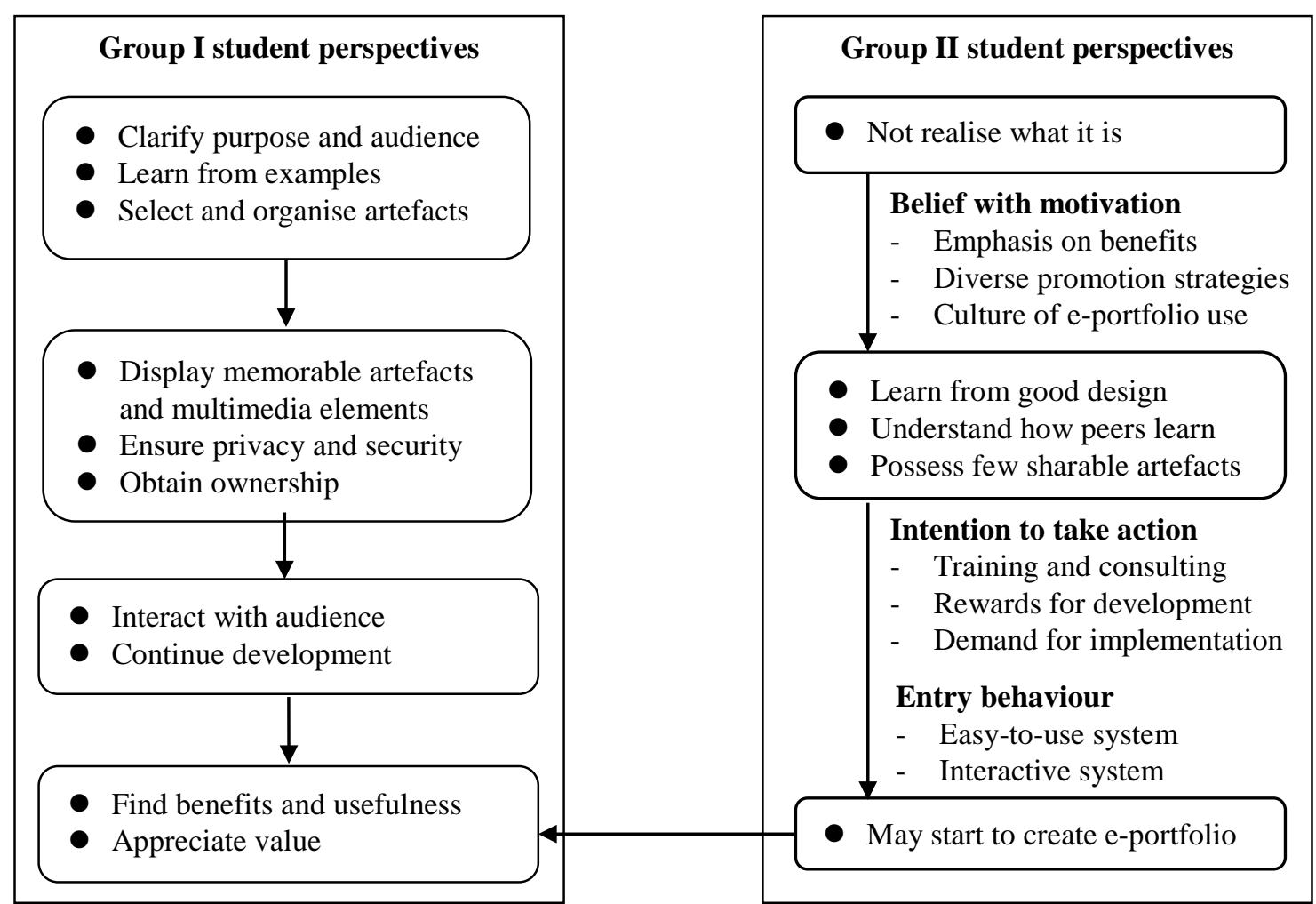

Figure 1. Student perspectives on developing e-portfolios

\section{Group II's descriptions of experiences}

Compared with the descriptions from Group I, the Group II interviewee perspectives on implementing e-portfolios were different, with the former characterised by taking real action (i.e., developing an e-portfolio), as shown in the right side of Figure 1. Initially, the students in Group II participated in school activities such as uploading organised learning notes, submitting class assignments, and participating in e-portfolio contests, to comply with class requirements. As Taiwanese students, who mature in a culture characterised by a relatively passive learning environment due to high pressure for preparing for achievement tests, the Group II interviewees had not realised the benefits or the value of developing e-portfolios and had less motivation to design one in the absence of effective promotional channels provided by teachers or schools. Despite awareness, Group II participants felt that schools should increase the number of promotional channels and provide persuasive strategies for encouraging the creation of e-portfolios. Overall, the teachers' requirements and the schools' culture for using e-portfolios influence their intention to participate in the development of personal e-portfolios:

I still think that it is the school's problem. The school doesn't do well in promoting e-portfolio creation. If many people created e-portfolios, I would be sure to create one. (code \# GII_06)

Prior to creating their own e-portfolios, most of the Group II interviewees also preferred to visit others' e-portfolios, including classmates and hyperlinked sites listed on the schools' servers. Consequently, Group II interviewees had opportunities to learn design techniques and content arrangement from these examples. However, instead of creating an e-portfolio for themselves, they only evaluated the learning outcomes of the originators and their own outcomes from self-reflection. The interviewees regarded themselves as having little outstanding content to present, and especially if the e-portfolios were available in the public domain, the demotivating factor was fear of possible humiliating exposure to poor performance. As a result, the 
e-portfolios might become another competition among the interviewees and their peers. In brief, for the Group II interviewees, the main deficit was a lack of sharable learning experiences to display online:

Like a mirror, I want to know what kind of ability I am lacking when reviewing others' e-portfolios. You may not think of something unless you find it, so you know what ability you need to enhance. (code \# GII_11)

In addition, the Group II interviewees indicated that if they decided to create an e-portfolio for optional participation in a contest, they felt greater rewards to be necessary, beyond their teachers adding entering a contest as a course requirement. They also hoped that deciding which web-based e-portfolio is outstanding would be based on every student's vote in a fair and public rating process. Since the Group II interviewees emphasised the importance of real-time interaction to gain feedback, share ideas, and display multimedia elements via the Internet, they wanted schools to offer more professional technical training and consulting services in order to better use the in-place systems. Some suggested replacing e-portfolios, either GT or CS, with social networking websites, such as Facebook and Plurk, which feature instant comment boards and animated displays (see external systems in Figure 2):

Facebook should be able to replace the original e-portfolio system since it is easier to use, and it is the trend. Companies can log in to Facebook to review my resume ... so they know you better in real life, not like the e-portfolio’s very stubborn interface. (code \# GII_09)

Based on the analyses results, perceptions of the Group II interviewees apparently include conflicts between beliefs about creating e-portfolios and motivations for creating one. Their intentions for creating e-portfolios would increase if schools provided diverse promotional channels to emphasise the benefits of using e-portfolios. As suggested by the Group II interviewees, schools should offer more technical support. Teachers may be able to play an important role in providing rewards or in demanding development of e-portfolios. Finally, interviewees from both Groups I and II agreed that ease of use and interactive systems are key elements for success in implementing e-portfolios in Taiwan's higher educational institutions.

\section{Results of analysing documents - interviewees' e-portfolios}

Since only school committees for contests had access to the e-portfolios, permission was finally obtained from 14 interviewees (out of 15 in the original group) to look at the websites containing their e-portfolio for 3 months in the spring of 2010. The analyses results show that some e-portfolio developers used a CS-based approach $(6,42.9 \%)$, some used a GT-based approach (2, 14.3\%), and some were hybrids (6, 42.9\%). According to the type of uploaded content, every interviewee's e-portfolio on the Internet had to contain at least one of four major segments: learning goals, learning activities, reflections on learning, or external systems (i.e., blogs and other interactive systems, such as Facebook and Plurk) (Figure 2). The second segment (i.e., learning activities) listed more content items as compared with the other segments. Notably, depending on the systems designed for e-portfolios by the schools, some items in the second segment appear in different categories. For example, the "Introduction" of some interviewees' e-portfolios presented awards received, but others presented awards in "Learning achievements, Learning experiences/records," or "Extracurricular activities."

Apparently, each segment correlates with the others. When evaluating learning outcomes, the interviewees had to plan before presenting the content related to learning activities, followed by reflections on learning activities. These e-portfolios not only induced self-reflection on learning, but also allowed communication with peers and teachers via other interactive systems. Since the interviewees indicated that they intended to document and share individual learning experiences, all of their e-portfolios included texts and photos. Other multimedia components further demonstrated the interviewees' special learning experiences. For example, six websites contained animations (42.9\%), five contained graphics (35.7\%); five had videos (35.7\%), and four included audio content (28.6\%). However, after the contests, only four interviewees updated the content of 
their e-portfolios. Some Group I and Group II interviewees clearly indicated that schools need to reinforce the value of continuously revising e-portfolios.

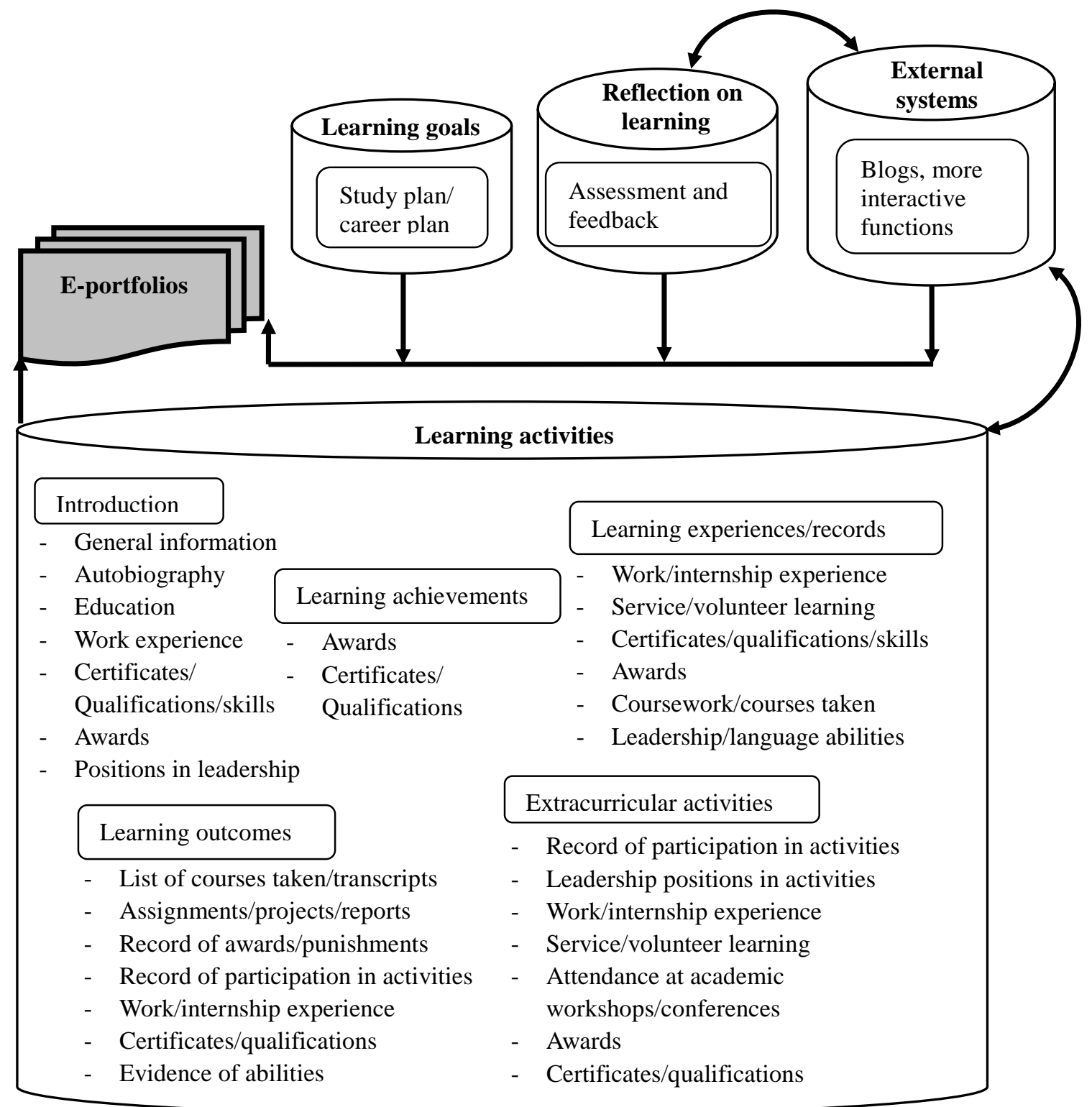

Figure 2. Four major segments of a website containing an e-portfolio

\section{Survey results - students, educators, and employers}

With the assistance of the interviewees (both Groups I and II), a survey to reach college and university students not interviewed directly was distributed to establish correlations among a wider spectrum of students and consistency with the interview data. The survey distribution resulted in 281 valid responses (response rate: 87.8\%). Cronbach's alpha for the overall responses was 0.83 (>0.7), indicating high consistency (Kannan \& Tan, 2005). Regarding student demographics, more males (62.3\%) than females (37.7\%) participated. Most 
were undergraduates, among whom first-year students accounted for $40.6 \%$, sophomores $13.2 \%$, juniors $13.5 \%$, and seniors $18.1 \%$. Most participants had no experience with designing a website (63.7\%). Half of the respondents $(141,50.2 \%)$ actually created their own e-portfolios, and among these, most students did so in their first year (88 out of 141, 62.4\%) and used the CS approach for development. Surprisingly, the remainder of the respondents used their e-portfolios only once.

With regard to the value of e-portfolio use, more than half of the respondents perceived the purpose to be to complete personal learning records (51.6\%) and demonstrate evidence of learning (20.3\%). In addition, $30.2 \%$ reported a potential audience for an e-portfolio could be prospective employers. This is consistent with the perspectives of the students who were interviewed. However, consistent with the interview results, most survey respondents were not aware of any organised contests for e-portfolios at their schools (60.1\%) but had visited e-portfolio websites (57.3\%). Of the respondents who received some information about contests for e-portfolios on campus (112 out of 281), only 38 respondents (33.9\%) actually participated, with $28.9 \%$ doing so in their first year. However, again consistent with the interview results, most of the students never updated the layout or content of their e-portfolios after the contests ended (25, 65.8\%). Overall, the survey respondents' perspectives on the implementation of e-portfolios support the interpretation of the interview data.

Meanwhile, we surveyed 48 Taiwanese college and university educators (over $80 \%$ are professors; response rate: 7.2\%) and 59 Taiwanese corporate recruiters (representing approaches in six industrial categories based on the Standard Industrial Classification defined by the National Statistics of Taiwan; response rate: 19.9\%) with regard to their perceptions of the students' e-portfolio development. Notably, despite the small sample that could lead to a positive or negative bias compared to a more general population, the thoughts of two e-portfolio audiences, educators and employers, remain valuable.

From the results, only $15.3 \%$ of the recruiters indicated that they had heard about e-portfolios from schools or online, a very different response from educators, $70.8 \%$ of whom were aware of e-portfolios. Accordingly, a majority of the recruiters had never visited students' e-portfolios (96.6\%), and educator responses were similar (64.6\%). Despite invitations to review students' e-portfolios for this study, the recruiters had little time for a complete examination. Similar to the educators, more than half of the recruiters (52.5\%) would browse the students' e-portfolio websites, on average, for 5 minutes. A small pilot study with four recruiters revealed that they spent, on average, approximately 89 seconds viewing one e-portfolio, and they preferred to verify students' educational backgrounds before considering previous learning experiences and achievements. Notably, teachers (i.e., educators) tended not to change syllabi by adding development of an e-portfolio as a course requirement.

In fact, many educators and recruiters held positive attitudes towards e-portfolios in relation to student employment searches. Specifically, $51.1 \%$ of the educators and $47.5 \%$ of the recruiters advocated integration of e-portfolios with the recruiting system to obtain more familiarity with students' educational performance. However, most recruiters (84.7\%) reported that they had received no notification from higher educational institutions of the existence of students' e-portfolios. The recruiters further reported that they focus on learning experiences (57.6\%) as well as the learning outcomes and achievements (74.6\%) found in students' e-portfolios. This response supports the reason for students to update meaningful artefacts pertaining to their learning activities, since these were deemed important by both the educators and recruiters. Compared to educator responses, fewer recruiters had interest in students' reflective statements on learning (32.2\%) in e-portfolios. Notably, many educators and recruiters (62.5\%) expressed concern that e-portfolio content might be copied from others.

\section{Summary - students perceptions of e-portfolio implementation}

This study reveals Taiwanese students' perceptions of the implementation of e-portfolios in higher educational institutions. Coded data accumulated from interviews provide several influential factors; cross-checking verifies consistency from different data sources as well as summarises this study's findings, as shown in Table 2. All the factors identified in this study can be further represented by using this study's proposed model, 
called the MAR stage model, which comprises the motivation (M), action (A), and reentry (R) stages. They can be regarded as the success determinants for processing each stage. Finally, for each factor and from one stage to another, this study reveals five critical success factors that represent guidelines for developing e-portfolios in Taiwanese higher education. To be noted, the three-stage process occurs repeatedly.

- Guideline 1 - Demonstrate the usefulness of e-portfolios for learning and employment. Students' motivations to prepare and update artefacts are due to the value of the use of e-portfolios by educators and administrators.

- Guideline 2 - Give opportunities to learn from example e-portfolios listed in schools' systems. Students gain encouragement and become enthusiastic towards creating their own e-portfolios.

- Guideline 3 - Emphasise the importance of ownership of an e-portfolio. Students have access to their e-portfolios after graduation and can continuously update content, such as certificates and technical skills gained post-graduation.

- Guideline 4 - Provide instructional training programs and consulting services. Students can develop e-portfolios despite low-level online publishing skills.

- Guideline 5 - Establish a culture for using e-portfolios. Students become accustomed to regularly updating their e-portfolios and willingly accept responsibility.

Table 2

Influential factors appearing in different data sources

\begin{tabular}{lcc}
\hline Factor & Frequency* $^{*}$ & Stage \\
\hline E-portfolio culture $^{1}$ & $(24,78)$ & $\mathrm{A}, \mathrm{R}$ \\
Easy to use $^{1,2,3}$ & $(16,58)$ & $\mathrm{A}$ \\
Required development $^{1,3,4}$ & $(24,56)$ & $\mathrm{A}$ \\
E-portfolio promotion $^{1,4}$ & $(25,54)$ & $\mathrm{M}$ \\
Time constraint $^{1,2,3,4}$ & $(21,53)$ & $\mathrm{R}$ \\
E-portfolio value $^{1,3,4}$ & $(21,51)$ & $\mathrm{M}, \mathrm{R}$ \\
Interaction $^{1,2}$ & $(19,39)$ & $\mathrm{R}$ \\
E-portfolio navigation $^{1,3}$ & $(20,37)$ & $\mathrm{M}, \mathrm{A}$ \\
E-portfolio ownership $^{1,2,3}$ & $(18,33)$ & $\mathrm{A}, \mathrm{R}$ \\
Encouragement $^{1,3}$ & $(20,31)$ & $\mathrm{A}$ \\
Training support $^{1,3}$ & $(18,27)$ & $\mathrm{A}, \mathrm{R}$ \\
Privacy and copyright concerns $^{1,4}$ & $(09,11)$ & $\mathrm{A}$ \\
\hline
\end{tabular}

* (number of interviewees, numbers of times the interviewees mentioned this factor)

${ }^{1}$ Data sources from Groups I and II interviews; ${ }^{2}$ Data sources from fourteen Group I e-portfolios; ${ }^{3}$ Data sources from student survey responses; ${ }^{4}$ Data sources from educator and recruiter survey responses

\section{Discussion and implications}

Differing perspectives from students might arise from research in different educational contexts (Buzzetto-More \& Nicole, 2010). Western students tend to regard e-portfolios as learning tools for self-reflection and learning evaluation since teachers emphasise active and evidence-based learning, and such students customarily update their e-portfolios without prompting. Although Taiwanese students display obvious concern for the practical value and benefits of developing e-portfolios, most perceive e-portfolios to be useful for showing capabilities (Lambe et al., 2013). This study reveals attitudinal factors, such as perceived usefulness, affect Taiwanese students' intended use of e-portfolios. Five guidelines are summarised from varied data sources obtained by adopting a mixed-method approach in order to explore the promotion of implementation of e-portfolios in Taiwan or in other countries having similar higher educational contexts. Based on the concept of TRA, a direct or indirect impact on individual behaviour can be used to predict the behaviour of individuals (Fishbein \& Ajzen, 1975). When the students immerse themselves in the process of creating e-portfolios, a three-stage model, consisting of motivation, action, and reentry (MAR stage model) (Figure 3) occurs repeatedly and portrays the links among the five guidelines. Guideline 1 helps motivate 
students to start preparing to develop their e-portfolios (M to A) or continuously updating them (A to R). Guideline 2 helps students gain more encouragement to update their e-portfolios (A to R) while having opportunities to visit others' e-portfolios examples (M to R). Guideline 3 helps students perceive their full control over their e-portfolios ( $\mathrm{R}$ to $\mathrm{M}$ ) and requires them to continuously update their e-portfolios after graduation ( $\mathrm{R}$ to $\mathrm{A}$ ). Guideline 4 helps students gain the more advanced information technology skills necessary to continuously develop their e-portfolios (A to R and R to A). Guideline 5 helps students recognise the value of developing an e-portfolio ( $\mathrm{R}$ to $\mathrm{M}$ ) and realising their responsibility for maintaining an e-portfolio (A to M). In other words, once the culture of e-portfolio use for learning and teaching exists, authors gain inspiration to include a variety of representative artefacts in their e-portfolios (Hart Research Associates, 2009; Lambe et al., 2013).

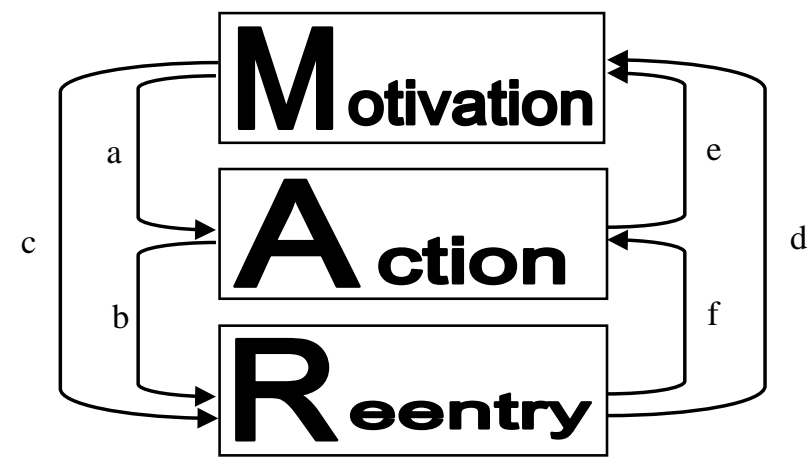

a: Guideline 1

b: Guideline 1, 2, 4

c: Guideline 2,

d: Guidelines 3, 5

e: Guideline 5

f: Guidelines 3, 4

Figure 3. MAR stage model

As the literature pertinent to users' perceptions of e-portfolios and the interview analysis results for this study indicate, the issue of ownership is critical to the maintenance of e-portfolios during schooling and afterwards. Thus, the e-portfolios developed and submitted by the students should be conveniently accessible on the Internet (Stefani et al., 2007). Regarding authenticity issues, several techniques are available for all e-portfolio audiences (Ward \& Moser, 2008), including those prior to submission and peer reviews specifically scrutinising data for authenticity and appending recommendations without editing. Oral or written questioning arising from the e-portfolios, which are likely to detect non-ownership, is another technique. Use of Turnitin or equivalent tools can also help resolve content authenticity issues.

Finally, based on the overall results, this study addresses the potential benefits gained from developing e-portfolios in higher education. If students maintain the currency of their e-portfolios, they can effectively demonstrate academic achievement, experiences in extra-curricular activities, as well as capabilities related to future education, applications for graduate school, and employment (Ward \& Moser, 2008). Through active and iterative updating, students can also customise the content or layout of their e-portfolios depending on the application for a targeted employer (Ward \& Moser, 2008). In brief, students encouraged to develop e-portfolios gain benefits from self-reflection and self-evaluation that facilitate preparation for interviews with potential employers (Chang et al., 2013). The current study suggests that institutions of higher education in Taiwan and countries with similar cultural backgrounds carefully consider which technological system is appropriate to launch for e-portfolios. Mobile practices are necessary considerations when adopting affirmative modes to motivate students' actively developing e-portfolios of their life-long learning (Maldonado, Khan, Moon, \& Rho, 2011; Merchant, 2012).

\section{Conclusions}

This study provides Taiwanese students' perceptions of, and experiences with, implementing e-portfolios and the factors affecting those perceptions. The adopted qualitative approach used data from semi-structured interviews with 30 college/university students and from document analysis of 14 websites containing e-portfolios. To provide more evidence to support the qualitative data analysis, one survey obtained 281 valid 
responses from non-interviewed college/university students, and another survey obtained 48 valid responses from university educators and 59 company recruiters. As a result, five critical success factors emerged. These factors are appropriate guidelines for implementing e-portfolio systems in Taiwan or countries with similar cultural backgrounds in higher education (e.g., China, Hong Kong, Korea, and Japan). Then, the MAR stage model, developed in this study, links the five guidelines to reveal success levels arising from implementing e-portfolios in an educational context.

The contributions of this study considering Taiwanese students' experiences and perceptions for development of e-portfolios in a higher education context apply to educational as well as entrepreneurial fields. Future studies could explore the application and value of e-portfolios for student-authors at different educational levels. Students with different backgrounds and personalities might also have different motivations for developing e-portfolios, and this issue could constitute the focus of future study. A larger-scale investigation of students' beliefs and attitudes would be valuable. Meanwhile, the gap between government policies related to universally promoting e-portfolio development and the reality of how students, educators and recruiters are confronting such policies should also be investigated in future studies. Design components can make e-portfolios more vivid, so websites displaying e-portfolios might be another worthy focus. As increasing numbers of mobile devices appear in use, studies could consider the effectiveness of e-portfolios in emerging technologies. Finally, in this study, the small sample size may have led to responses with positive or negative bias compared to a more generalised student sample. However, arguably, the survey remains valuable for discovering the various thoughts of two e-portfolio audiences, educators and employers.

\section{References}

Abrami, P. C., \& Barrett, H. (2005). Directions for research and development on electronic portfolios. Canadian Journal of Learning and Technology, 31, 1-15. Retrieved from http://www.cjlt.ca/index.php/cjlt/article/view/92/86

Babbie, E. R. (2007). The practice of social research (11th ed.). Melbourne: Thomson Wadsworth.

Barrett, H. (2010). Balancing the two faces of ePortfolios. Educação, Formação \& Tecnologias, 3(1), 6-14. Retrieved from http://eft.educom.pt/index.php/eft/article/viewFile/161/102

Barrett, H., \& Carney, J. (2005). Conflicting paradigms and competing purposes in electronic portfolio development. Retrieved from http://electronicportfolios.org/portfolios/LEAJournal-BarrettCarney.pdf

Buzzetto-More, N. \& Nicole, A. (2010). Applications of e-portfolios for value added assessment. In N. Buzzetto-More \& A. Nicole (Eds.), The e-portfolio paradigm: Informing, educating, assessing, and managing with e-portfolios (pp. 225-246). Santa Rosa, CA: Informing Science Press.

Chang, C. C., Liang, C., Tseng, K. H., Tseng, J. S., \& Chen, T. Y. (2013). Were knowledge management abilities of university students enhanced after creating personal blog-based portfolios? Australasian Journal of Educational Technology, 29(6), 916-931. Retrieved from http://ajet.org.au/index.php/AJET/article/view/462

Clark, J. E., \& Eynon, B. (2009). E-portfolios at 2.0: Surveying the field. Peer Review, 11, 18-23. Retrieved from http://www.aacu.org/publications-research/periodicals/e-portfolios-20\%E2\%80\%94surveying-field

Creswell, J. W. (2003). Research design: Qualitative, quantitative, and mixed methods approaches (2nd ed.). Thousand Oaks, CA: Sage.

Dalton, J. C. (2007). Concluding observations and implications of e-portfolios for student affairs leadership and programming. New Directions for Student Services, 119, 99-106. doi:10.1002/ss.252

Fishbein, M., \& Ajzen, I. (1975). Belief, attitude, intention and behavior: An introduction to theory and research. Reading, MA: Addison-Wesley.

Ford, C., Hartley, S. L., \& Lumsden, J. (2008). Using eportfolios for job searching. Inter/National Coalition for Electronic Portfolio Research: Connections, 3, 1-5. Retrieved from http://ncepr.org/connectionsJul08.pdf

Gibson, D., \& Barrett, H. (2003). Directions in electronic portfolio development. Technology and Teacher Education, 2(4), 559-576. Retrieved from http://www.citejournal.org/vol2/iss4/general/CITEGibsonGeneral2.pdf

Gillham, B. (2005). Research interviewing: The range of techniques. New York, NY: Open University Press. 
Hart Research Associates. (2009). Learning and assessment: Trends in undergraduate education. Washington, DC: Author. Retrieved from http://www.aacu.org/membership/documents/2009MemberSurvey_Part1.pdf

Herner-Patnode, L. M., \& Lee, H. J. (2009). A capstone experience for preservice teachers: Building a web-based portfolio. Educational Technology \& Society, 12(2), 101-110. Retrieved from http://www.ifets.info/journals/12_2/8.pdf

Johnson, G., Hsieh, P. H., \& Kidwai, K. (2007). Perceived value and persistence of web publishing skills: Implications for e-portfolio systems. International Journal on E-Learning, 6, 379-394. Retrieved from http://www.editlib.org/p/21971/

Jun, M. K., Anthony, R., Achrazoglou, J., \& Coghill-Behrends, W. (2007). Using ePortfolioTM for the assessment and professional development of newly hired teachers. TechTrends: Linking Research \& Practice to Improve Learning, 51, 45-50. doi:10.1007/s11528-007-0055-3

Kannan, V. R., \& Tan, K. C. (2005). Just in time, total quality management, and supply chain management: Understanding their linkages and impact on business performance. Omega, 33, 153-162. doi:10.1016/j.omega.2004.03.012

Kocoglu, Z. (2008). Turkish EFL student teachers' perceptions on the role of electronic portfolios in their professional development. The Turkish Online Journal of Educational Technology, 7, 71-79. Retrieved from http://www.tojet.net/articles/v7i3/738.pdf

Lambe, J., McNair, V., \& Smith, R. (2013). Special educational needs, e-learning and the reflective e-portfolio: Implications for developing and assessing competence in pre-service education. Journal of Education for Teaching: International Research and Pedagogy, 39, 181-196. Retrieved from http://eprints.ulster.ac.uk/22362/1/2013_eportfolio_article.pdf

Lewis, J., \& Ritchie, J. (2003). Generalising from qualitative research. In J. Ritchie \& J. Lewis (Eds.), Qualitative research practice: A guide for social science students and researchers (pp. 263-286). London: Sage.

Lin, Q. (2008). Preservice teachers' learning experiences of constructing e-portfolios online. The Internet and Higher Education, 11, 194-200. doi:10.1016/j.iheduc.2008.07.002

Lopez-Fernandez, O., \& Rodriguez-Illera, J. L. (2009). Investigating university students' adaptation to a digital learner course portfolio. Computers \& Education, 52, 608-616. doi:10.1016/j.compedu.2008.11.003

Lumsden, J. A. (2007). Development and implementation of an e-portfolio as a university-wide program. New Directions for Student Services, 119, 43-63. doi:10.1002/ss.248

MacDonald, L., Liu, P., Lowell, K., Tsai, H., \& Lohr, L. (2004). Part one: Graduate student perspectives on the development of electronic portfolios. TechTrends: Linking Research \& Practice to Improve Learning, 48, 52-55. doi:10.1007/BF02763357

Maldonado, U. P. T., Khan, G. F., Moon, J., \& Rho, J. J. (2011). E-learning motivation and educational portal acceptance in developing countries. Online Information Review, 35, 66-85. doi:10.1108/14684521111113597

Mason, R., Pegler, C., \& Weller, M. (2004). E-portfolios: An assessment tool for online courses. British Journal of Educational Technology, 35, 717-727. doi:10.1111/j.1467-8535.2004.00429.x

Merchant, G. (2012). Mobile practices in everyday life: Popular digital technologies and schooling revisited. British Journal of Educational Technology, 43, 770-782. doi:10.1111/j.1467-8535.2012.01352.x

Ministry of Education. (2015). Annual report of administration performance. Retrieved from http://www.edu.tw/pages/list.aspx?Node=1264\&Type=1\&Index=7\&wid=45a6f039-fcaf-44fe-830e-50882 aab1121

National Youth Commission. (2012). Project for enhancing implementation of youth employment. Retrieved from http://www.yda.gov.tw/Content/Downloads/List.aspx?SiteID=563426067575657313\&MmmID=65320127 7324715071

Ntuli, E., Keengwe, J., \& Kyei-Blankson, L. (2009). Electronic portfolios in teacher education: A case study of early childhood teacher candidates. Early Childhood Education Journal, 37, 121-126. doi:10.1007/s10643-009-0327-y

Patton, M. Q. (2002). Qualitative research and evaluation methods. Thousand Oaks, CA: Sage.

Stefani, L., Mason, R., \& Pegler, C. (2007). The educational potential of e-portfolios. London: Routledge. 
Taylor, J., Dunbar-Hall, P., \& Rowley, J. (2012). The e-portfolio continuum: Discovering variables for e-portfolio adoption within music education. Australasian Journal of Educational Technology, 28(8), 1362-1381. Retrieved from http://ajet.org.au/index.php/AJET/article/view/776

Tonni, I., \& Oliver, R. G. (2013). Acceptability of a reflective e-portfolio instituted in an orthodontic specialist programme: A pilot study. European Journal of Dental Education, 17(3). Retrieved from http://onlinelibrary.wiley.com/doi/10.1111/eje.12038/pdf

Tsai, H., Lowell, K., Liu, P., MacDonald, L., \& Lohr, L. (2004). Part two: Graduate student perspectives on the development of electronic portfolios. TechTrends: Linking Research \& Practice to Improve Learning, 48, 56-60. doi:10.1007/BF02763358

van Tartwijk, J., Driessen, E., van der Vleuten, C., \& Stokking, K. (2007). Factors influencing the successful introduction of portfolios. Quality in Higher Education, 13, 69-79. doi:10.1080/13538320701272813

Ward, C., \& Moser, C. (2008). E-portfolios as a hiring tool: Do employers really care? EDUCAUSE Quarterly, $31,13-14$.

Zubizrreta, J. (2009). The learning portfolio: Reflective practice for improving student learning. San Francisco, CA: John Wiley \& Sons, Inc.

Corresponding author: Pei-Hsuan Hsieh, peihsuan@mail.ncku.edu.tw

Australasian Journal of Educational Technology @ 2015.

Please cite as: Hsieh, P-H., Lee, C-I. \& Chen, W-F. (2015). Students’ perspectives on e-portfolio development and implementation: A case study in Taiwanese higher education. Australasian Journal of Educational Technology, 31(5), 641-656. 